\title{
CD I a-positive Langerhans cells and their relationship with E-cadherin in ameloblastomas and keratocystic odontogenic tumors
}

Leonardo Araújo Mello ${ }^{1}$, Andréia Leal Figueiredo ${ }^{2}$, Eduardo Antônio Gonçalves Ramos ${ }^{3}$, Clarissa Araújo Silva Gurgel ${ }^{1}$, Manoela Domingues Martins ${ }^{4}$, Claúdia Roberta Leite Vieira de Figueiredo ${ }^{5}$, Patrícia Ramos Cury $^{6}$, Ricardo Luiz Cavalcanti de Albuquerque Júnior ${ }^{7}$, Luciana Maria Pedreira Ramalho ${ }^{8}$, Jean Nunes dos Santos ${ }^{1}$

${ }^{1}$ Laboratory of Oral Surgical Pathology, Department of Oral Pathology, School of Dentistry, Federal University of Bahia, Salvador, Bahia, Brazil; ${ }^{2}$ Department of Dental Public Health, School of Dentistry, Federal University of Bahia, Salvador, Bahia, Brazil; ${ }^{3}$ Laboratory of Pathology and Biology Molecular, Oswaldo Cruz Foundation, Salvador, Bahia, Brazil; ${ }^{4}$ Departament of Oral Pathology, School of Dentistry, Federal University of Rio Grande do Sul, Porto Alegre, Rio Grande do Sul, Brazil; ${ }^{5}$ Department of General Pathology, Federal University of Paraíba, João Pessoa, Paraíba, Brazil; ${ }^{6}$ Department of Periodontics, School of Dentistry, Federal University of Bahia, Salvador, Bahia, Brazil; ${ }^{7}$ Laboratory of Morphology and Structural Biology, Aracaju, Sergipe, Bahia, Brazil; ${ }^{8}$ Department of Stomatology, School of Dentistry, Federal University of Bahia, Salvador, Bahia, Brazil

BACKGROUND: Ameloblastomas and keratocystic odontogenic tumors (KOTs) are lesions that are characterized by locally invasive growth and cause extensive bone destruction. In addition, it is known that E-cadherin influences the adhesion of Langerhans cells (LCs) to keratinocytes.

OBJECTIVE AND METHODS: The aim of this study was to investigate, using immunohistochemistry, the distribution of CDIa-positive cells in ameloblastomas and KOTs and their relationship with E-cadherin, in comparison to calcifying cystic odontogenic tumor (CCOT).

RESULTS: The CDIa-positive LCs were observed in I I ameloblastomas and KOTs. All of the cases of CCOT showed CDIa-positive LCs and a significant difference was found when this tumor was compared with ameloblastomas $(P<0.05$, Mann-Whitney test). A statistically significant difference was also noted when comparing CD la-positive LCs between CCOTs and KOTs $(P<0.05$, Mann-Whitney test). Lower expression of E-cadherin in ameloblastomas (AMs) in relation to KOTs and CCOTs $(P<0.05$, Fisher test) was observed. There was no correlation between E-cadherin and CDIa-positive LCs between all odontogenic tumors that were studied ( $P>0.05$, Spearman test).

CONCLUSION: A quantitative difference of CDIa-positive cells between AMs and KOTs in comparison to CCOTs was observed. This permits to speculate that a depletion of CDIa-positive LCs might influence the local

Correspondence: Jean Nunes dos Santos, Faculdade de Odontologia, Avenida Araújo Pinho, 62, Canela, Salvador-BA 40110-150, Brazil. Tel: 55713283 9019, Fax: 5571 32838962, E-mail: jeanunes@ufba.br Accepted for publication November 17, 2012 invasiveness of ameloblastomas and KOTs. Furthermore, it is suggested that E-cadherin mediates cell adhesion in these tumors.

J Oral Pathol Med (20I3) 42: 454-46I

Keywords: dendritic cell; E-cadherin; Langerhans cell; odontogenic tumors

\section{Introduction}

Ameloblastomas (AMs) and keratocystic odontogenic tumors (KOTs) are benign tumors derived from the odontogenic epithelium that are characterized by a fibrous and mature stroma and the lack of involvement of odontogenic ectomesenchyme (1). These tumors show a locally invasive growth pattern and cause extensive bone destruction $(2,3)$.

Langerhans cells (LCs), an immature dendritic cell type that resides in epithelial tissue, are believed to play a fundamental role in the presentation of tumor antigens to $\mathrm{T}$ cells inside lymph nodes, producing an antitumor response (4-7). An increase in the number of these cells has been associated with a better prognosis of different tumors (8-13), although their role in odontogenic tumors has not yet been established (14-23). Little is known about the participation of LCs in odontogenic tumors, as the presence of these cells has been merely mentioned based almost exclusively on case reports and not appropriately discussed by previous studies (14-23).

E-cadherin is a glycoprotein that is responsible for the adhesion between epithelial cells whose main function is 
related to morphogenesis and the maintenance of the integrity of epithelial tissue (24-26). Regarding odontogenic tumors, E-cadherin might be associated with cellular differentiation and invasiveness, but no differences between AMs and tooth germs have been observed $(27,28)$. In addition, E-cadherin plays a role in the adhesion of LCs to keratinocytes; this protein is the main component responsible for the retention of LCs in the epidermis, exerting an important influence on the transport and adhesion of these cells to the lymph nodes $(29,30)$.

We hypothesized that a lower expression of E-cadherin may influence the adhesion of LCs to epithelial cells, resulting in a depletion of CD1a-positive cells, as this could exert influence on the local invasiveness of AMs and KOTs. This study investigated the participation of CD1a-positive cells in AMs and KOTs. In addition, we evaluated the role of E-cadherin and compared its expression to calcifying cystic odontogenic tumor (CCOT), a type of non-invasive odontogenic tumor that is characterized by an ameloblastoma-like epithelium (1) .

\section{Material and methods}

After approval of the study by the Ethics Committee, 38 cases of odontogenic tumors retrieved from the files of the Pathological Anatomy Service of the School of Dentistry, Federal University of Bahia, were investigated. The sample consisted of 10 solid AMs, 10 unicystic AMs, and 18 KOTs (10 primary tumors, three recurrent tumors, and five tumors that were associated with nevoid basal cell carcinoma syndrome. Four cases of CCOTs were included for comparative purposes. For confirmation of the histopathological diagnosis, the cases were reviewed by a single experienced pathologyst (J.N.S) who used the criteria established by the World Health Organization (1). Clinical data obtained from the request forms of the anatomopathological exams indicated that $21 \%$ patients were males and $21 \%$ were females, with a mean age of 32 years (range 6-82). Thirtyone cases were located in the mandible, whereas seven cases occurred in the maxilla.

Immunohistochemistry was performed on paraffin waxembedded sections ( $3 \mu \mathrm{m}$ thick). The tissue sections were deparaffinized in xylene (two times for $10 \mathrm{~min}$ ) and rehydrated with absolute alcohol (two times for $5 \mathrm{~min}$ ) at room temperature. For CD1a, heat-induced antigen retrieval was performed (boiling the sections in EDTA, $\mathrm{pH}$ 8.0, for $30 \mathrm{~min}$ at $97^{\circ} \mathrm{C}$ ). The same antigen retrieval technique was used for E-cadherin, but the sections were boiled in citrate monohydrate solution ( $\mathrm{pH}$ 6.0). Endogenous peroxidase activity was blocked by immersion of the tissue sections in phosphate-buffered saline that contained $0.3 \%$ hydrogen peroxide for $30 \mathrm{~min}$. Next, monoclonal antibodies against CD1a (clone O10, dilution 1:50; Dako Cytomation, Glostrup, Denmark) and E-cadherin (clone NCH-38, dilution 1:100; Dako Cytomation) were diluted in antibody diluent in addition to background-reducing components (Dako Corporation, Carpinteria, CA, USA) and incubated with the antibodies for $60 \mathrm{~min}$ at room temperature. The Envision ${ }^{\mathrm{TM}}$ polymer (Dako Corporation) was then applied for $30 \mathrm{~min}$ at room temperature, followed by the development of the reaction with 3'3-diaminobenzidine (Dako Corporation) as chromogenic peroxidase substrate for $5 \mathrm{~min}$ in a dark chamber. Afterward, the slides were counterstained with Mayer's hematoxylin. Lining epithelium and one case of pyogenic granuloma served as positive controls. The negative control consisted of replacement of the primary antibody with another antibody of the same isotype.

Histological analysis included the total count of the LCs on both parenchyma and the stroma of the tumors. The shape of the cells was described.

The histomorphometric assessment was carried out by a previously trained observer using high-definition light microscopy $\times 200$ (Axiostar Plus; Zeiss, 2008 Göttingen, Germany) in up to five high-power fields using a digital camera for recording (Axiocam Icc3; Zeiss, 2008), and the observer was blind to the microscopic diagnosis. LCs count per square millimeter $\left(56 \mu / \mathrm{mm}^{2}\right)$ was performed using specific software (Axiovision Rel 4.8; Zeiss, 2008). Quantification of cells was calculated by the mean count found in each case.

The expression of E-cadherin was analyzed semiquantitatively at $200 \times$ magnification by attributing four scores: zero, no expression; $+1,<20 \%$ positive cells; $+2,20-50 \%$ positive cells, and $+3,>50 \%$ positive cells (31). The immunolabeled cells were identified by a brown color irrespective of staining intensity.

Differences between the groups were tested by using the Kruskal-Wallis, Mann-Whitney, and Fisher's $\chi^{2}$ tests. The correlation between CD1a and E-cadherin was analyzed by using Spearman's correlation coefficient. All statistical calculations were performed by using the SPSS 13.0 program (SPSS Inc., Chicago, IL, USA). A $P$ value $<0.05$ was considered to be statistically significant.

\section{Results}

CD1a-positive LCs were detected in $65.8 \%(n=25)$ of the odontogenic tumors. CD1a-positive LCs were more frequently found in the tumor parenchyma, either in epithelial islands or in the intermediate layer of the cystic lining epithelium. CD1a-positive cells that exhibited a dendritic shape were mainly found inside the tumor parenchyma, whereas round cells were observed on the border of the tumor parenchyma and around blood vessels. The overall mean density of CD1a-positive LCs in all of the odontogenic tumors was 3.82 ( $\mathrm{SD} \pm 5.77$; Fig. 1).

The CD1a-positive LCs were observed in 55\% $(n=11)$ of AM cases. These cells were more frequently evident within the tumor parenchyma either on epithelial islands or in the basal or intermediate layers of the epithelial lining of cystic spaces. Rarely, CD1a-positive LCs were seen in areas exhibiting squamous metaplasia. The mean count of CD1apositive LCs in AMs was $5.02(\mathrm{SD} \pm 6.76)$, and this mean was greater than that observed for both histological types of the odontogenic tumors that were studied. No significant difference in the mean count of CD1a-positive cells was found between the solid and unicystic AMs $(P>0.05$, Mann-Whitney test). Non-significant inflammation was found in 15 ameloblastomas cases, and no significant difference was found between those with and without inflammation $(P>0.05$, Mann-Whitney test). 

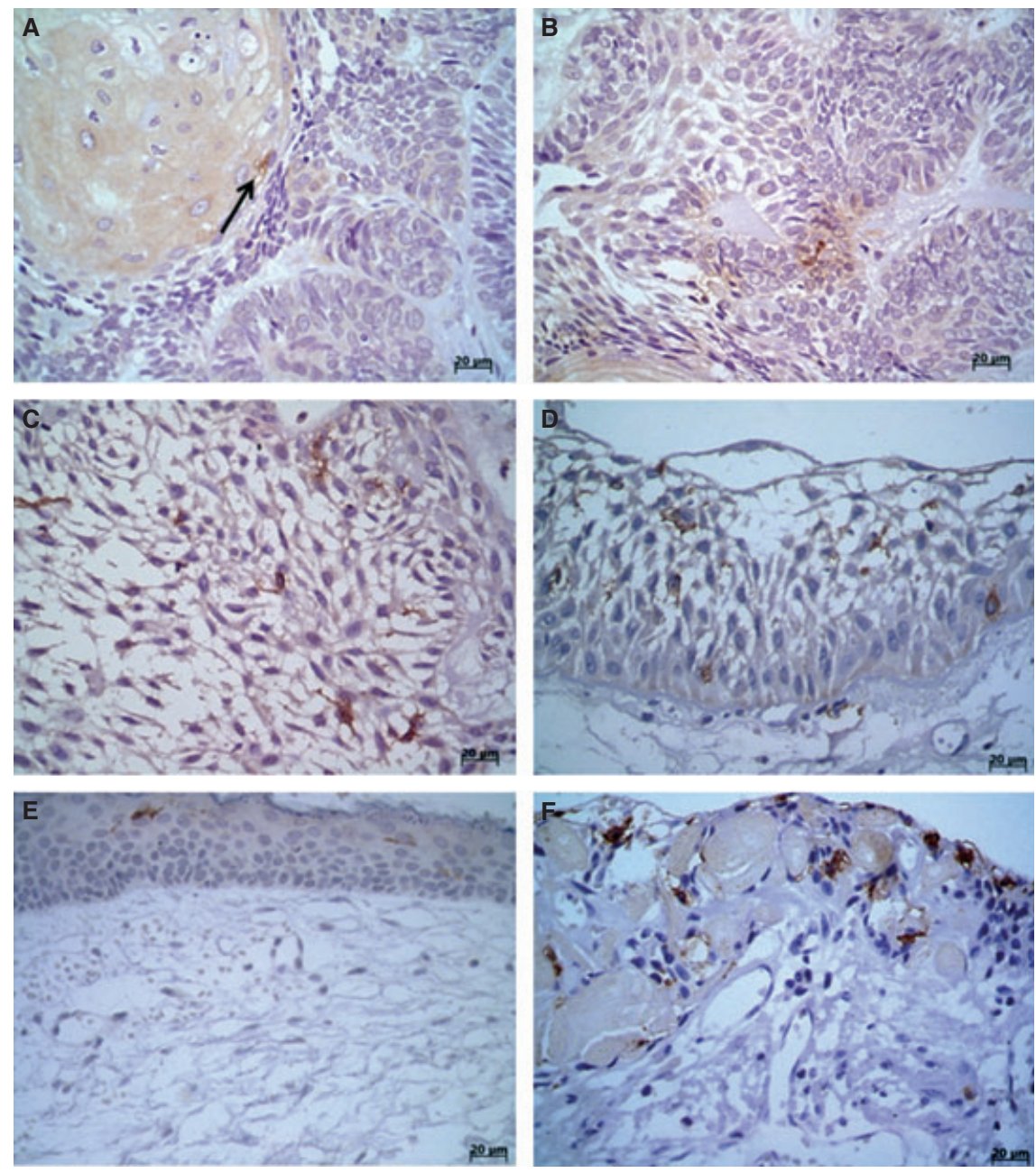

Figure 1 Solid ameloblastoma: (A) CD1a-positive dendritic cells located on the peripheral area corresponding to squamous metaplasia (arrow). (B) CD1apositive cells located within the tumor parenchyma. (C) Several CD1a-positive dendritic cells immersed in an area composed of stellate reticulum-like tumor cells. Unicystic ameloblastoma: (D) CD1a-positive dendritic cells located on basal cells and stellate reticulum-like cells. Keratocystic odontogenic tumor. (E) CD1a-positive dendritic cells located on the suprabasal layer and upper layers. Calcifying cystic odontogenic tumor: (F) CD1a-positive dendritic cells located on the odontogenic epithelium and surrounding ghost cells.

The CD1a-positive LCs were observed in approximately $78 \%(n=14)$ of KOT cases. These cells were more evident in the suprabasal or intermediate layers of the epithelial lining of the fibrous cystic wall. The mean count of CD1apositive LCs in KOTs was 1.38 ( $\mathrm{SD} \pm 1.55$ ), and this indicates a lower density of CD1a-positive LCs. Significant inflammation was found in five KOTs cases, and nonsignificant inflammation was found in 13 cases. Primary KOTs with inflammation showed higher number of CD1apositive LCs $(n=9.2)$ than primary KOT without inflammation $(n=7)$, recurrent KOT without inflammation $(n=1.6)$, and syndrome KOTs without inflammation $(n=7.2)$. However, no significant difference was observed between the different types of KOTs that were studied $(P>0.05$, Kruskal-Wallis test).

All of cases of CCOTs showed CD1a-positive LCs. They were present in the basal columnar cells and intermediate layer that were composed of stellate reticulum-like cells and surrounding ghost cells. The mean density of CD1a-positive LCs corresponded to 12.8 ( $\mathrm{SD} \pm 9.12$ ), indicating a high number of these cells in CCOT. In addition, a significant difference was found when the CCOT was compared with AMs $(P=0.047$, Mann-Whitney test; Fig. 2). Similarly, there was also a statistically significant difference when comparing CD1a-positive LCs between CCOT and KOT $(P=0.006$, Mann-Whitney test; Fig. 3).

The mean count of CD1a-positive LCs between AM and KOT cases showed no significant difference $(P>0.05$, Kruskal-Wallis test).

Table 1 shows the mean count of CD1a-positive LCs in AMs, KOTs, and CCOTs.

E-cadherin was observed as cytoplasmatic and membranous labeling in $76.32 \%(n=29)$ of 38 odontogenic tumors. This immunostaining was observed predominantly in the central region of the AMs tumor nests and corresponded to the stellate reticulum. In addition, the suprabasal layers of cystic epithelium lining were also seen in unicystic AM and KOTs (Fig. 4). These findings are in accordance with the semiquantitative analysis (Table 2). In addition to the intermediate layer, Ecadherin was seen surrounding ghost cells present in CCOT. 


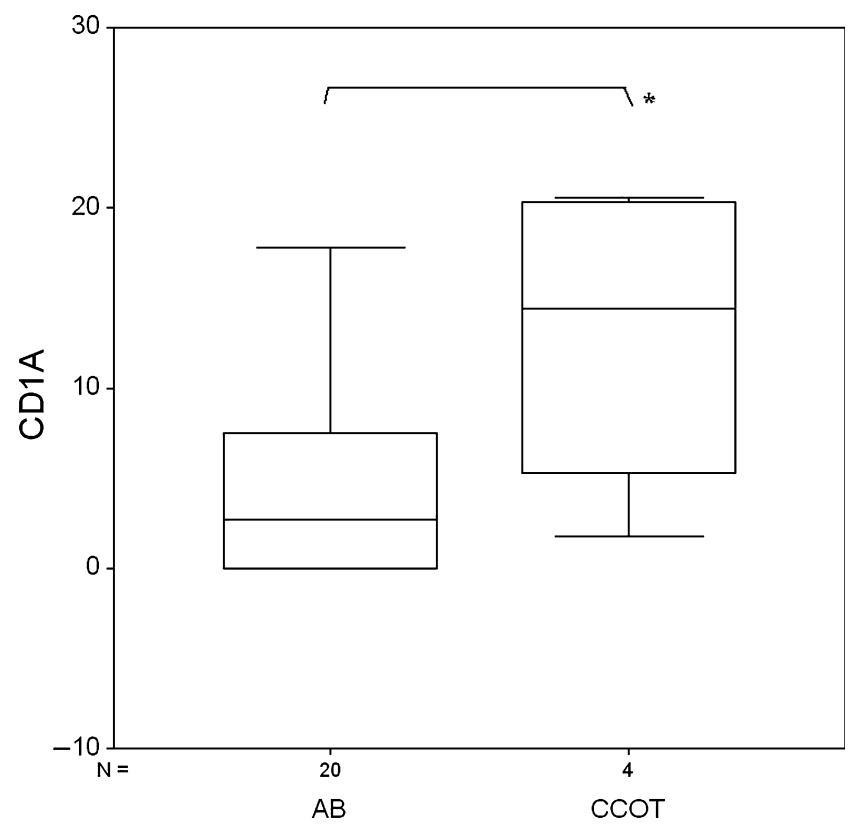

Figure 2 Mean count of CD1a-positive cells in ameloblastomas and cystic calcifying odontogenic tumor $(* P=0.0470)$.

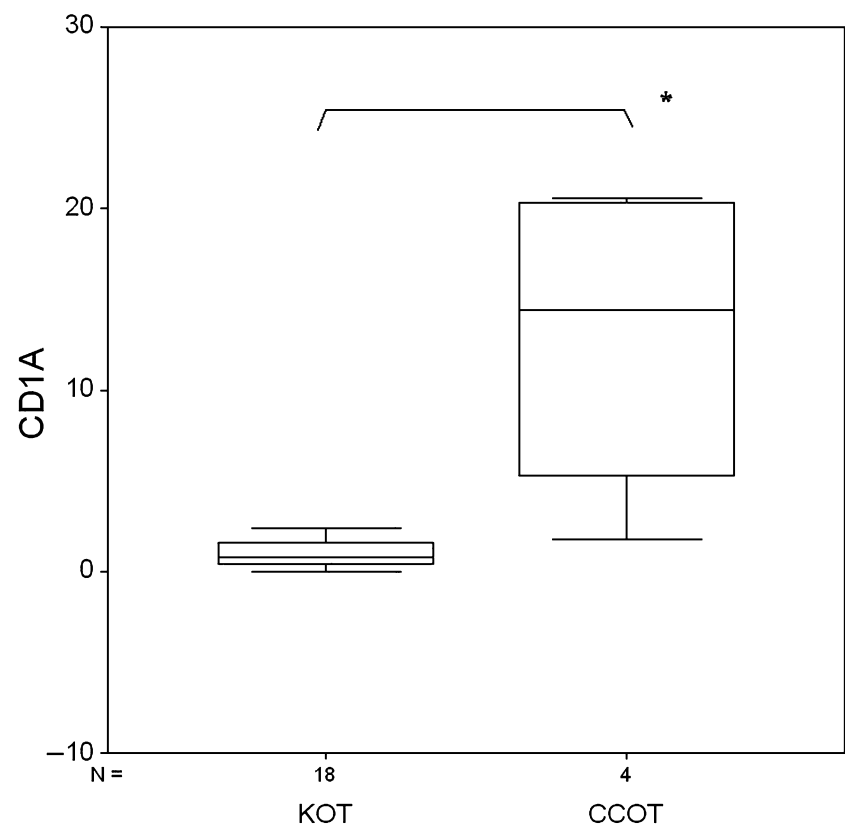

Figure 3 Mean of CD1a-positive cells in keratocystic odontogenic tumor and cystic calcifying odontogenic tumor $\left({ }^{*} P=0.006\right)$.
CDIa and E-cadherin in odontogenic tumors

Mello et al.

Eleven (55\%) AMs cases were immunostained for Ecadherin. Most cases exhibited moderate staining (score +2$)$, which indicated positivity between $20 \%$ and $50 \%$ of tumors cells. All cases of KOTs and CCOTs showed significantly higher immunostaining for E-cadherin than that observed for AMs, respectively $(P=0.000$ Fisher test). Table 2 shows the score of immunostaining for E-cadherin in odontogenic tumors.

There was no correlation between E-cadherin and CD1apositive LCs in the odontogenic tumors that were studied, including CCOTs $(P>0.05$, Spearman test).

\section{Discussion}

This study showed no statistically significant difference in the number of CD1a-positive LCs between AMs and KOTs. However, the density of CD1a-positive LCs in CCOTs was significantly higher in comparison to AMs and KOTs. This finding might contribute to the locally invasive growth of AMs and KOTs. The lower expression of E-cadherin in AMs in relation to KOT was observed, suggesting its important role in mediating cell adhesion in odontogenic tumors.

The distribution of LCs within the epithelial component of odontogenic tumors that were observed in this study was similar to that reported in previous investigations (20-23, 32, 33). Furthermore, dendritic LCs were frequently seen inside the tumor parenchyma, whereas round cells were mainly found along the borders of the parenchyma and around blood vessels, such an observation was also noted by Dultra et al. (13). On the basis of these findings, we speculated that LCs may not reach maturity within the tumor as the surface of CD1 molecules decrease on mature dendritic cells (34). Indeed, the round morphology of the cells along the borders of the parenchyma and around blood vessels may indicate that these cells did not mature for efficient antigen presentation (35). The defective maturation may be a result of negative signals of inhibitory cytokines that were secreted by the neoplastic cell population or the inflammatory and/or endothelial cells, which were present in the tumor stroma.

In this study, no significant difference in the density of LCs was observed between the follicular and plexiform patterns of solid AMs, or between these AMs and the unicystic AMs. Such findings suggest that the variability in their morphological patterns is not influenced by the LC population. Despite this observation, Murase et al. (15) also found a low immunoexpression of S100-positive LCs in AMs. It should be noted that in this study, LCs were rarely detected in the areas of squamous metaplasia that was seen in solid AMs. This finding might be related to the fact that

Table 1 Variations in number of CD1a-positive cells in odontogenic tumors

\begin{tabular}{|c|c|c|c|c|c|}
\hline & $\begin{array}{l}\text { Solid amelo- } \\
\text { blastoma } \\
\text { Mean }(S D)\end{array}$ & $\begin{array}{l}\text { Unicystic amelo- } \\
\text { blastoma } \\
\text { Mean }(S D)\end{array}$ & $\begin{array}{c}\text { Non-syndrome keratocystic odon- } \\
\text { togenic tumor } \\
\text { Mean }(S D)\end{array}$ & $\begin{array}{c}\text { Syndrome keratocystic odonto- } \\
\text { genic tumor } \\
\text { Mean }(S D)\end{array}$ & $\begin{array}{c}\text { Cystic calcifying odonto- } \\
\text { genic tumor }\end{array}$ \\
\hline $\begin{array}{l}\text { CD1a-positive } \\
\text { cells }\end{array}$ & $7.4 \pm 7.64$ & $2.64 \pm 4.77$ & $1.37 \pm 1.64$ & $1.44 \pm 1.45$ & $12.8 \pm 9.12$ \\
\hline
\end{tabular}



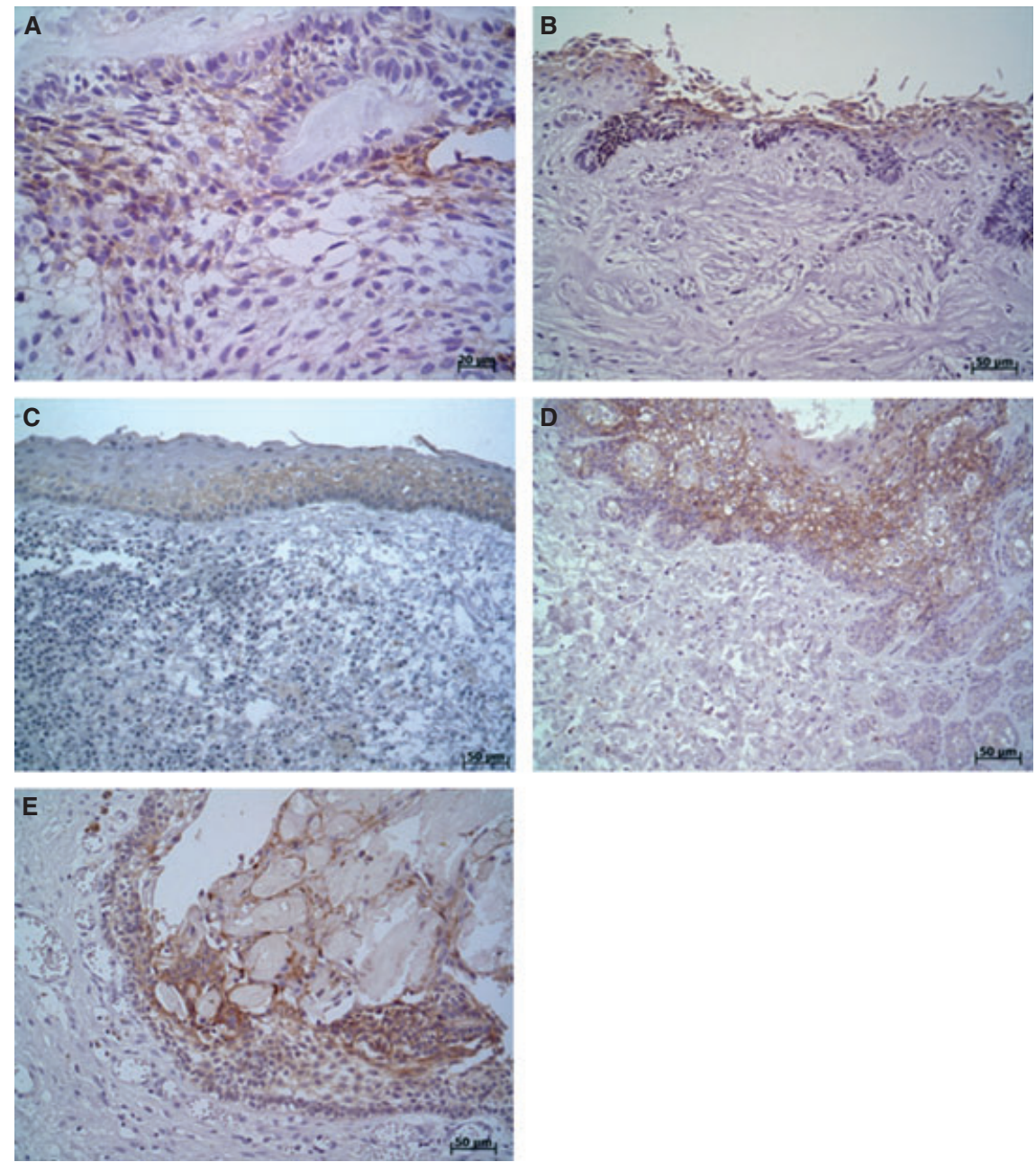

Figure 4 Solid ameloblastoma: (A) Folicular pattern showing variable labeling of E-cadherin especially in the central region. Unicystic ameloblastoma: (B) E-cadherin present in the suprabasal and superficial layers. Keratocystic odontogenic tumor: (C) Variable labeling of E-cadherin located especially on the suprabasal layer; note loss of immunostaining influenced by the inflammation. (D) Thicker epithelial lining displaying strong labeling of E-cadherin on intermediate layer; note loss of immunostaining in epithelial buds and islets. Calcifying cystic odontogenic tumor: (E) E-cadherin located on the columnar basal cells, suprabasal cells with aspects of stellate reticulum.

Table 2 Score of immunostaining for E-cadherin in odontogenic tumors

\begin{tabular}{lcccc}
\hline & \multicolumn{5}{c}{ Scores } \\
\cline { 2 - 5 } \multicolumn{1}{c}{ Odontogenic tumors } & $\begin{array}{c}\text { Score 0 } \\
\text { (n) }\end{array}$ & $\begin{array}{c}\text { Score 1 } \\
\text { (n) }\end{array}$ & $\begin{array}{c}\text { Score 2 } \\
\text { (n) }\end{array}$ & $\begin{array}{c}\text { Score 3 } \\
\text { (n) }\end{array}$ \\
\hline $\begin{array}{l}\text { Solid ameloblastoma } \\
\text { Unicystic ameloblastoma }\end{array}$ & 3 & 4 & 2 & 1 \\
$\begin{array}{l}\text { Non-syndrome keratocystic } \\
\text { odontogenic tumor }\end{array}$ & 0 & 0 & 3 & 1 \\
$\begin{array}{l}\text { Syndrome keratocystic odonto- } \\
\text { genic tumor }\end{array}$ & 0 & 0 & 0 & 13 \\
$\begin{array}{l}\text { Cystic calcifying odontogenic } \\
\text { tumor }\end{array}$ & 0 & 0 & 1 & 3 \\
\hline
\end{tabular}

the metaplastic epithelium poorly interacts with LCs. This characteristic might be either associated with a lower quantity of chemotactic factors for LCs or with the secretion of chemotactic stimuli that inhibit these cells, suggesting poor immunocompetent activity of the metaplastic epithelium (36).

The mean count of CD1a-positive LCs was greater in AMs than in KOTs, as the former showed no immunoreactivity in almost half of the cases. This finding is not consistent with the work of Murase et al. (15) who observed S-100-positive LCs in a few cases of AMs. Although low immunogenicity may be related to the locally aggressive behavior and high rate of recurrence, it is not possible to attribute this difference to the LC counts found in AMs and KOTs because they exhibit similar biological behavior. However, a statistically significant difference between CCOT (a non-invasive odontogenic tumor) and other tumors studied was observed. This finding permits speculation that differences in the biological behavior between invasive and non-invasive odontogenic tumors might be attributed to this cell population. Despite the scarcity or absence of dendritic cells in some tumors, Gabrilovich et al. (37) and Oyama et al. (38) suggest this to be attributed to the lack of recruitment of these cells or their insufficient 
development as result of the activation of vascular endothelial growth factor (VEGF) secreted by many tumors, which could influence the differentiation of dendritic cells by inhibiting Nf-K $\beta$. Furthermore, it is important to state that dendritic cell apoptosis has been reported $(39,40)$. Other immune system cell components and a greater number of cases might explain this matter.

It has been postulated that the increased frequency of LCs into the tumor can be explained by tumor growth that causes local tissue damage and, consequently, the recruitment of inflammatory cells to the tumor site (10). In this study, no significant difference was observed between CD1a-positive LCs and the degree of inflammation response. Similar results have been reported in other studies that investigated odontogenic lesions such as KOTs, dentigerous cysts, dental granulomas, and radicular cysts $(32,33,41)$. These data indicate that an increase or decrease in the CD1a-positive dendritic cell population does not directly influence the magnitude of the $\mathrm{T}$ cell-dependent immune response in odontogenic tumors. However, it should be noted that primary KOTs with inflammation tended to show a more expressive count of CD1a-positive LCs than primary KOTs without inflammation, recurrent tumors without inflammation, and syndrome tumors without inflammation.

E-cadherin is a protein that is expressed by epithelial cells. It participates in the mechanism of cell adhesion and seems to be involved in various processes of morphogenesis and cell differentiation (25). Disturbances in the regulation and expression of E-cadherin can alter the mechanism of cell differentiation and trigger processes that result in tumor invasion (25).

Most of the AMs and KOTs showed immunoreactivity to E-cadherin in the tumor parenchyma, a finding that is consistent with the role played by this protein in the intercellular adhesion of epithelial cells $(24,25)$. However, our results showed a marked lower expression of E-cadherin in AMs in relation to KOTs and CCOTs. This supports its local invasiveness pattern (42-44). Despite these findings in AMs, several studies have demonstrated lower expression of E-cadherin regarding different tumors with aggressive biological behavior (27). However, other authors report that benign tumors of an epithelial origin exhibit a pattern of E-cadherin expression that is similar to that seen in healthy tissue, suggesting the preservation of the function of this adhesion molecule after neoplastic transformation (45). Such an outcome seems to have occurred with KOTs.

With respect to the unicystic and solid AMs, there was no difference in the E-cadherin expression, corroborating the findings of Alves Pereira et al. (28), although Feng et al. (46) have reported the opposite. It is possible that differences in the biological behavior of both tumors is determined by factors other than those directly associated with the expression of this molecule.

This study showed strong immunostaining for E-cadherin in central areas of tumor islands in AMs that morphologically resemble the stellate reticulum of the enamel organ. These data suggest that this neoplastic epithelial component preserves the characteristics of cytodifferentiation of the odontogenic epithelium. In addition, strong expression of E-cadherin was observed in the suprabasal layer of the lining epithelium of KOTs, suggesting a high degree of cell adhesion between parenchymatous cells of this tumor. However, lower expression of staining intensity seems to have occurred in cases of primary KOT with inflammation when compared with the other groups. According to Kaplan and Hirshberg (47), the inflammatory process may contribute to the loss of structural characteristics of the lining epithelium in KOTs. Therefore, as E-cadherin is a glycoprotein that is responsible for epithelial architecture and integrity $(26,30)$, it is possible that the presence of the inflammatory infiltrate in the KOTs that were studied here contributed to the loss of expression of this protein.

We found no significant correlation between the expression of E-cadherin and LC density in AMs, KOTs, and CCOTs. However, despite the association between the LC population and this adhesion molecule, Galan and Ko (48) also found no significant difference in the density of LCs in squamous cell carcinomas and pseudoepitheliomatous hyperplasias, which are tumors characterized by low and high levels of E-cadherin expression, respectively. Hubert et al. (5) observed an association between low LC density and the low expression of E-cadherin in the epithelium of squamous cell carcinomas and intraepithelial squamous lesions of the uterine cervix. The authors suggested that the lower expression of E-cadherin in these lesions reduces the density of LCs and thus compromises the capacity of dendritic cells to recognize tumor antigens. Therefore, it is possible that the lack of correlation between both markers as observed in this study could be attributed to the impairment of CD1a-positive cells' interaction with E-cadherin when analyzing odontogenic epithelial tumors.

Finally, this study showed a quantitative difference of CD1a-positive cells between AMs and KOTs in comparison with CCOTs, a non-invasive odontogenic tumor with an ameloblastomatous epithelium. This permits speculation that a depletion of CD1a-positive cells might influence the local invasiveness of Ams and KOTs. Furthermore, although we did not demonstrate correlation between E-cadherin and CD1a-positive LCs, it is suggested that E-cadherin mediates cell adhesion in these tumors.

\section{References}

1. Barnes L, Eveson JW, Reichart P, Sidransky D. World Health Organization of tumours, pathology \& genetics, head and neck tumours. Lyon: IARC press, 2005.

2. Melo LA, Gurgel CA, Ramos EA, et al. Keratocystic odontogenic tumour: an experience in the Northeast of Brazil. Srp Arh Celok Lek 2011; 139: 291-7.

3. Ide F, Mishima K, Yamada H, Kikuchi K, Saito I, Kusama K. Intraosseous ameloblastoma with a prominent extraosseous component: pitfalls in diagnosis. Head Neck Pathol 2010; 4: 192-7.

4. Laguens G, Coronato S, Laguens R, Portiansky E, Di Girolamo V. Human regional lymph nodes draining cancer exhibit a profound dendritic cell depletion as comparing to those from patients without malignancies. Immunol Lett 2002; 84: $159-62$.

5. Hubert P, Bousarghin L, Greimers R, Franzen-Detrooz E, Boniver J, Delvenne P. Production of large numbers of Langerhans' cells with intraepithelial migration ability in vitro. Exp Dermatol 2005; 14: 469-77. 
6. La Rocca G, Anzalone R, Corrao S, et al. CD1a downregulation in primary invasive ductal breast carcinoma may predict regional lymph node invasion and patient outcome. Histopathology 2008; 52: 203-12.

7. Lin A, Schildknecht A, Nguyen LT, Ohashi PT. Dendritic cells integrate signals from the tumor microenvironment to modulate immunity and tumor growth. Immunol Lett 2010; 27: 77-84.

8. Wischatta M, Sprinzl GM, Gunkel AR, Hussl B, Romani N, Schrott-Fischer A. Dendritic cells in selected head and neck tumors. Ann Otol Rhinol Laryngol 2000; 109: 56-62.

9. Eisenthal A, Polyvkin N, Bramante-Schreiber L, Misonznik F, Hassner A, Lifschitz-Mercer B. Expression of dendritic cells in ovarian tumors correlates with clinical outcome in patients with ovarian cancer. Hum Pathol 2001; 32: 803-7.

10. Baleeiro RB, Bergami-Santos PC, Tomiyoshi MY, et al. Expression of a dendritic cell maturation marker CD83 on tumor cells from lung cancer patients and several human tumor cell lines: is there a biological meaning behind it? Cancer Immunol Immunother 2008; 57: 265-70.

11. Fujisawa $Y$, Nabekura $T$, Nakao $T$, et al. The induction of tumor-specific CD4+ $\mathrm{T}$ cells via major histocompatibility complex class II is required to gain optimal anti-tumor immunity against B16 melanoma cell line in tumor immunotherapy using dendritic cells. Exp Dermatol 2008; 18: 396403.

12. Raspollini MR, Baroni G, Taddei GL. Langerhans cells in lichen sclerosus of the vulva and lichen sclerosus evolving in vulvar squamous cell carcinoma. Histol Histopathol 2009; 24: 331-6.

13. Dultra FK, Barros AC, Schaer-Barbosa H, et al. Immunohistochemical assessement of CD1a-positive Langerhans cells and their relationship with E-cadherin in minor salivary gland tumors. J Oral Pathol Med 2012; 41: 47-53.

14. Asano M, Takahashi T, Kusama K, et al. A variant of calcifying epithelial odontogenic tumor with Langerhans cells. J Oral Pathol Med 1990; 19: 430-4.

15. Murase N, Tatemoto Y, Iwai Y, Okada Y, Mori M. Langerhans cells in odontogenic tumours and cysts as detected by S-100 protein immunohistochemistry. Basic Appl Histochem 1990; 34: 135-41.

16. Takata T, Ogawa I, Miyauchi M, Ijuhin N, Nikai H, Fujita M. Non-calcifying Pindborg tumor with Langerhans cells. J Oral Pathol Med 1993; 22: 378-83.

17. Philipsen HP, Reichart PA. Calcifying epithelial odontogenic tumour: biological profile based on 181 cases from the literature. Oral Oncol 2000; 36: 17-26.

18. Poomsawat S, Punyasingh J. Calcifying epithelial odontogenic tumor: an immunohistochemical case study. J Mol Histol 2007; 38: 103-9.

19. Wang YP, Lee JJ, Wang JT, et al. Non-calcifying variant of calcifying epithelial odontogenic tumor with Langerhans cells. J Oral Pathol Med 2007; 36: 436-9.

20. Candido GA, Viana KA, Watanabe S, Vencio EF. Peripheral dentinogenic ghost cell tumor: a case report and review of the literature. Oral Surg Oral Med Oral Pathol Oral Radiol Endod 2009; 108: 86-90.

21. Mesquita AT, Santos CR, Gomez RS, Jorge J, León JE, De Almeida OP. Central granular cell odontogenic tumor: a histopathologic and immunohistochemical study. Ann Diagn Pathol 2009; 13: 405-12.

22. Eversole LR. Odontogenic fibroma, including amyloid and ossifying variants. Head Neck Pathol 2011; 5: 335-43.

23. Mosqueda-Taylor A, Martốnez-Mata G, Carlos-Bregni R, et al. Central odontogenic fibroma: new findings and report of a multicentric collaborative study. Oral Surg Oral Med Oral Pathol Oral Radiol Endod 2011; 112: 349-58.
24. Tang A, Amagai M, Granger LG, Stanley JR, Udey MC. Adhesion of epidermal Langerhans cells to keratinocytes mediated by E-cadherin. Nature 1993; 361: 82-5.

25. Heymann R, About I, Lendahl U, Franquin JC, Obrink B, Mitsiadis TA. E- and N-cadherin distribution in developing and functional human teeth under normal and pathological conditions. Am J Pathol 2002; 160: 2123-33.

26. Kohl K, Klein E, Koch S, Schnautz S, Bieber T. Migration and differentiation of Langerhans cell precursors. Eur J Cell Biol 2004; 83: 805-11.

27. Kumamoto H, Ooya K. Expression of E-cadherin and alphacatenin in epithelial odontogenic tumors: an immunohistochemical study. J Oral Pathol Med 1999; 28: 152-7.

28. Alves Pereira KM, Do Amaral BA, Dos Santos BR, Galvão HC, Freitas RA, Souza LB. Immunohistochemical expression of E-cadherin and beta-catenin in ameloblastomas and tooth germs. Oral Surg Oral Med Oral Pathol Oral Radiol Endod 2010; 109: 425-31.

29. Ardavin C, Martốnez Del Hoyo G, Martốn P, et al. Origin and differentiation of dendritic cells. Trends Immunol 2001; 22: 691-700.

30. Jakob T, Brown MJ, Udey MC. Characterization of E-cadherin-containing junctions involving skin-derived dendritic cells. J Invest Dermatol 1999; 112: 102-8.

31. Yoo J, Park S, Kang CS, Kang SJ, Kim BK. Expression of E-cadherin and p53 proteins in human soft tissue sarcomas. Arch Pathol Lab Med 2002; 126: 33-8.

32. Piattelli A, Rubini C, Iezzi G, Fioroni M. CD1a-positive cells in odontogenic cysts. J Endod 2002; 28: 267-8.

33. Meira TM, Melo LA, Gurgel CA, et al. Density of Langerhans cells in the keratocysitic odontogenic tumor. J Bras Patol Med Lab 2010; 46: 135-41.

34. Cao X, Sugita M, Van Der Wel N, et al. CD1 molecules efficiently present antigen in immature dendritic cells and traffic independently of MHC Class II during dendritic cell maturation. J Immunol 2002; 169: 4770-7.

35. Banchereau J, Briere F, Caux C, et al. Immunobiology of dendritic cells. Annu Rev Immunol 2000; 18: 767-811.

36. Al-saleh W, Giannini SL, Jacobs N, et al. Correlation of thelper secretory differentiation and types of antigen-presenting cells in squamous intraepithelial lesions of the uterine cervix. J Pathol 1998; 184: 283-90.

37. Gabrilovich DI, Chen HL, Girgis KR, et al. Production of vascular endothelial growth factor by human tumors inhibits the functional maturation of dendritic cells. Nat Med 1996; 2: 1096-103.

38. Oyama T, Ran S, Ishida T, et al. Vascular endotelial growth factor affects dendritic cell maturation through the inhibition of nuclear factor-kappa $\mathrm{b}$ activation in hemopoietic progenitor cells. J Immunol 1998; 160: 1224-32.

39. Arany I, Tyring SK, Brysk H, et al. Induction by interferongamma of its receptor varies with epithelial differentiation and cell type. Arch Dermatol Res 1998; 290: 331-4.

40. Ito M, Minamiya Y, Kawai H, et al. Tumor-derived TGFbeta1 induces dendritic cell apoptosis in the sentinel lymph node. J Immunol 2006; 176: 5637-43.

41. Santos LC, Ramos EAG, Gurgel CA, Santana EJ, Santos JN. Immunohistochemical detection of Langerhans cells in dental granulomas and radicular cysts. J Mol Histol 2007; 38: 201-5.

42. Belli E, Rendine G, Mazzone N. Ameloblastoma relapse after 50 years from resection treatment. J Craniofac Surg 2009; 20: 1146-9.

43. González-Alva P, Tanaka A, Oku Y, et al. Keratocystic odontogenic tumor: a retrospective study of 183 cases. J Oral Sci 2008; 50: 205-12.

44. Ngwenya SP, Raubenheimer EJ, Noffke CE. Internal morphology of ameloblastomas: a study of 24 resected specimens. 
Oral Surg Oral Med Oral Pathol Oral Radiol Endod 2009; 108: 754-62.

45. Downer CS, Speight PM. E-Cadherin expression in norma, hyperplastic and malignant oral epithelium. Eur $J$ Cancer $B$ Oral Oncol 1993; 29: 303-5.

46. Feng Y, Zhou YM, Hua CG, Tang XF, He DQ. Expression of twist in different subtype of ameloblastomas. Oral Surg Oral Med Oral Pathol Oral Radiol Endod 2009; 108: 565-70.

47. Kaplan I, Hirshberg A. The correlation between epithelial cell proliferation and inflammation in odontogenic keratocyst. Oral Oncol 2004; 40: 985-91.

48. Galan A, Ko CJ. Langerhans cells in squamous cell carcinoma vs. pseudoepitheliomatous hyperplasia of the skin. J Cutan Pathol 2007; 34: 950-2.

\section{Acknowledgements}

This study was supported by CAPES (Coordenação de Aperfeiçoamento de Pessoal de Ensino Superior, Brasil) and CNPq (Conselho Nacional de Desenvolvimento Científico e Tecnológico).

\section{Conflict of interest}

None declared. 